\title{
Humeanizing Kant's Aesthetics
}

\section{Richard Fumerton}

I ALMOST ALWAYS FEEL that I understand Hume and I am almost never confident that I understand Kant. As a kind of interpretive tool, when I read Kant I always ask myself a) what Hume would have thought about the subject matter under discussion, and b) how Hume would have tried to explain Kant's views had they been his own. In these few brief comments I want to try to understand a certain part of Kant's aesthetics by asking myself in what ways it differs from the corresponding part of Hume.

Let me begin with a couple of disclaimers. The first and most important is that I am not a Kant scholar, and when I talk about my interpretation of Kant's aesthetics I mean only to report the view that keeps suggesting itself to me on a reading of the primary literature.

The second disclaimer concerns the part of Kant's aesthetics to which I want to restrict my comments. In effect I want to compare Hume's and Kant's meta-aesthetic views. I want to compare their views about the meaning of aesthetic judgments. Just as in ethics it seems possible to distinguish two sorts of questions, meta-ethical questions (questions dealing with the meaning of ethical statements) and normative ethical questions (questions dealing with the things or kinds of things to which ethical terms apply), so too it seems possible to distinguish questions about the meaning of aesthetic judgments (meta-aesthetic judgments) from questions about the things to which our aesthetic concepts apply. The difficulty with asking questions about Kant's meta-aesthetic views is simply that he didn't explicitly make the distinction. Yet as the father of the analytic/synthetic distinction, he was certainly in a position to recognize it. We could ask him to distinguish truths about the concept of beauty from truths about the various forms and structures that we can correctly conclude are beautiful. But the distinction is nevertheless not explicitly made as far as I can see in the Critique of Judgment and I am never quite sure which views Kant puts forward are meta-aesthetic and which are normative. 
Whereas Kant spent the better part of a book dealing with aesthetic judgments, Hume devotes only a subsection of his Treatise of Human Nature to the analysis of judgments about beauty. His meta-aesthetic view seems very similar to his meta-ethical view. Both judgments about virtue and vice, and beauty and deformity, for Hume, seem to reduce to judgments about the way in which we respond with pleasure and satisfaction or their opposites to the conception or perception of things. About vice Hume says in Book III, Part I, Section I of the Treatise:

So that when you pronounce any action or character to be vicious, you mean nothing, but that from the constitution of your nature you have a feeling or sentiment of blame from the contemplation of it.

About beauty Hume says in Book II, Part I, Section VIII of the Treatise:

. . . beauty is such an order and construction of parts, as either by the primary constitution of our nature, by custom, or by caprice, is fitted to give a pleasure and satisfaction to the soul.

In the case of virtue and vice Hume explicitly links his view to the prevalent views about secondary qualities, and I assume he would treat aesthetic properties similarly. The distinction between primary and secondary qualities was recognized by many of Hume's and Kant's contemporaries. The rough idea is that some properties of physical objects (the primary properties) are literally present in the objects as well as being represented in the minds of conscious beings, while other properties of objects (the secondary properties) exist in objects only as the power to produce in conscious beings certain psychological states. The sourness of the lemon, for example, exists only in the lemon as the power to produce in people certain sensations. If there were no people to respond with taste sensations, there would be no sourness in the lemon. In extending the analogy to moral and aesthetic properties, Hume was suggesting that the virtue or beauty of something exists in that thing only as the power to produce in people certain affective responses. The details of the interpretation of Hume are by no means uncontroversial. The secondary quality analogy suggests that he takes the relevant dispositions that define virtue and 
beauty to be identified with those of "normal" or "standard" people, but there are other (I think more persuasive) passages that suggest that Hume was endorsing a radical relativism often summarized by the cliché that beauty is in the eye of the beholder-a cliché that, I think, essentially captures the philosophically important truth about aesthetic properties.

To what extent does Kant's meta-aesthetics lend itself to a similar kind of secondary property analysis? Like Hume, Kant was obviously sympathetic to the idea that it is through a certain kind of subjective feeling that one makes aesthetic judgments. Unlike Hume (or at least my interpretation of Hume) he clearly didn't want to endorse either the radical relativistic view or even the view that we can understand assertions about beauty in terms of assertions about the dispositions of "normal" people to react with a certain kind of pleasure upon the perception of things. In his discussion of the antinomy of taste Kant refers with obvious sarcasm to the Humean view that judgments of taste are radically subjective and relative:

The following proposition contains the first of these [commonplace views about taste] and is used by everyone who lacks taste but tries to escape censure: Everyone has his own taste. (210)

The implication of such a view is that there is nothing to argue about when it comes to aesthetics. If when you say that something is beautiful you mean only to assert that you are disposed to react to it with a certain kind of satisfaction or pleasure and when $I$ deny that the same thing is beautiful I mean only to assert that I don't have that disposition, then clearly you and I are not contradicting each other and there doesn't seem to be anything to argue about. Yet clearly Kant thinks that there can be genuine disagreement over the aesthetic qualities of things. And of course he is right in suggesting that our aesthetic discourse would seem on the face of it to suggest that there are genuine aesthetic disputes. People do argue about whether a painting, for example, is beautiful or not, and they seem to argue as if there is some fact of the matter.

The relativistic Humean obviously has difficulty accommodating this feature of aesthetic discourse which is of special concern to Kant. Nor does Kant allow himself to call upon the "standard person" analysis of aesthetic judgments. He explicitly rejects the view that "a judgment of taste 
deserves to be considered correct only insofar as there happen to be many people agreeing on it" (219, his emphasis). It seems clear that his main concern with such a view (a view again modeled on the analysis of secondary properties) is that it misses the claim of necessary universal assent characteristic of our judgments about beauty. When I judge that an object is beautiful I am not merely predicting that as it so happens most other people will respond with a similar sort of pleasure. Rather I am, according to Kant, committed to the view that other people must respond in a similar way. In short Kant would have no objections to a Humean account of what it means to say of something that is merely agreeable or pleasant, but when we are talking about beauty we leave, if not subjectivity, at least relativity behind and advance claims of necessary universal assent.

But do we need to leave the basic Humean model for understanding value judgments behind? As we all know, Kant insisted that to make an aesthetic judgment one must adopt a kind of disinterested perspective. In a number of places Kant seems to make clear that this involves a certain process of abstraction whereby we strip ourselves of all those idiosyncratic features that distinguish us from other conscious intellectual beings. The pleasure or satisfaction with which we react in making an aesthetic judgment is the pleasure or satisfaction of a "pure" self or, one might say, a self qua self.

Taste is the ability to judge an object, or a way of presenting it, by means of a liking or disliking devoid of all interest. The object of such a liking is called beautiful. (53)

Now this is a rather epistemological way of putting the point. But if we ask what meta-aesthetic view it suggests it is surely the same kind of dispositional analysis that Hume put forth:

To say of something that it is beautiful is to say that a completely disinterested observer would respond to it with satisfaction.

Such an account would still be in the spirit of a secondary quality analysis but it would differ from a Humean account or a "standard" person 
account. Instead of talking about how the person judging would respond or how normal people would respond, Kant is talking about how disinterested people would respond. If this were Kant's meta-aesthetic view then we could understand in a fairly clear way the sense in which an aesthetic judgment necessarily involves universality. If qua disinterested observer I respond in a certain way to something wouldn't it follow that any other disinterested observer would respond in the same way? It would in effect be an instance of the general principle (accepted as definitionally true even by Hume): same cause, same effect. Since there is nothing to distinguish me qua disinterested subject from you qua disinterested subject, you and I will of necessity respond in the same way to the same stimulus.

Notice by the way that the view I sketched above is not only compatible with the general approach of a Humean account that tries to understand beauty in terms of the power to produce pleasure, but it is suggested in a very crude way by some of the things Hume says about value judgments. In Book III, Part II, Sec. II of the Treatise, after identifying the subject matter of value judgments with powers to produce certain sentiments, Hume adds an interesting qualification:

Nor is every sentiment of pleasure or pain, which arises from characters or actions, of that peculiar kind which makes us praise or condemn. ... Tis only when a character is considered in general, without reference to our particular interest, that it causes such a feeling or sentiment as denominates it morally good or evil.

I don't want to exaggerate the analogy but one can certainly see at least a bridge between this sort of view of value judgments and a Kantian conception of aesthetic judgments.

Let me conclude these brief remarks by admitting that I have no great confidence that one can capture Kant's meta-aesthetic view in terms of his simply identifying the subject matter of aesthetic judgments with conditional statements describing the way in which disinterested people would respond to certain forms and objects. It is after all difficult to square such an interpretation with all of the things Kant says about aesthetic judgments, including his apparent insistence that one should contrast aesthetic judgments with cognitive judgments. On the other hand I suspect that if 
Kant were Hume and Kant were trying to describe his meta-aesthetic view, the proposed analysis of aesthetic judgments would be a perfectly straightforward and natural way of presenting the fundamental Kantian thesis, a way of presenting it that would make the interpretation of Kant's aesthetics much easier. 